\title{
Actinomadura meyerae osteitis following wound contamination with hay in a woman in France: a case report
}

\author{
Emilie Bonnet ${ }^{1}$, Xavier Flecher ${ }^{2}$, Sebastien Paratte ${ }^{2}$, Jean-Noël Argenson², Didier Raoult ${ }^{1}$, Pierre-Edouard Fournier ${ }^{1 *}$
}

\begin{abstract}
Introduction: Mycetoma is a chronic granulomatous infection caused by environmental fungi or bacteria. It affects dermal and subcutaneous tissues, with putative contiguous extension to muscles or bones. While common in tropical and subtropical areas, mycetoma is rare in Europe.

Case presentation: We describe a case of Actinomadura meyerae osteitis in a 49-year-old Caucasian woman who suffered a tibia open fracture contaminated with hay; to the best of our knowledge the first case of autochthonous A. meyerae infection reported in France. The bacterium was cultivated from a bone biopsy. Following surgical osteosynthesis and six months of treatment with cotrimoxazole, our patient made a full recovery.

Conclusion: Our case report suggests that A. meyerae is a potential agent of wound infection in farm workers in contact with hay.
\end{abstract}

\section{Introduction}

Infections caused by Actinomadura species, Grampositive bacilli that belong to the family Thermomonosporaceae within the order Actinomycetales, are common in tropical and subtropical areas [1]. They are mostly caused by Actinomadura madurae and Actinomadura pelletieri. In Europe, only four cases of Actinomadura infections have been reported to date, caused by Actinomadura sp. [2,3], A. madurae [4] and Actinomadura sputi [5]. We report the first case of Actinomadura meyerae infection in a patient who developed osteitis following contamination of an open fracture wound with hay.

\section{Case presentation}

A 49-year-old Caucasian woman working on a farm in Vichy, France, experienced an open fracture of the left tibia caused by a hook lifting a haystack. Subsequently, she was admitted to hospital. The fracture was reduced with a locking compression plate (Synthes, Oberdorf, Switzerland). Then, five days later, our patient developed a fever of $38.5^{\circ} \mathrm{C}$, and oral treatment with amoxicillinclavulanic acid, $6 \mathrm{~g} /$ day, was started; eight days after

\footnotetext{
* Correspondence: pierre-edouard.fournier@univmed.fr

${ }^{1}$ Federation de Microbiologie, Hôpital de la Timone, Marseille, France

Full list of author information is available at the end of the article
}

starting this treatment, the first antibiotic was replaced with oral ciprofloxacin $(1.0 \mathrm{~g} /$ day $)$ for three months. During that time, the cutaneous wound healed, but successive X-rays showed that bone healing was not obtained. Seven months following surgery, our patient broke her tibia locking compression plate while walking. Then, four weeks later, she was admitted to hospital. On examination, our patient had swelling and pain of the leg at the fracture site without any evident clinical sign of infection. X-rays showed a non-union of the tibia at the fracture site and the broken locking compression plate. Her blood test results showed a leukocyte count of $7.39 \times 10^{9}$ cells/L (73\% polymorphonuclear cells, $24.9 \%$ mononuclear cells), a $C$ reactive protein level of $1 \mathrm{mg} / \mathrm{mL}$, and an erythrocyte sedimentation rate of $5 \mathrm{~mm} /$ first hour. The patient underwent removal of the locking compression plate, immediately followed by an intra-medullary nailing associated with a cancellous autologous bone graft harvested on the homolateral iliac crest. A peri-operative bone biopsy of the fracture site was performed in sterile conditions and sent to the microbiology laboratory of the Timone Hospital, Marseille, France. Direct microscopic analysis showed the presence of numerous polymorphonuclear leukocytes, but no bacteria were detected using Gram stain.

\section{C)


The biopsy was cultivated in aerobic and anaerobic conditions at $37^{\circ} \mathrm{C}$ for one month. Plates were checked for bacterial growth twice a week. On the 28th day of culture, white colonies that were convex, powdery and adherent were detected on blood-enriched Columbia agar (Figure 1A). The strain was named Timone, according to the name of our hospital. Gram staining demonstrated that the colonies were made of irregular and extensively branched Gram-positive bacilli less than $1 \mu \mathrm{m}$ in diameter (Figure 1B). The bacterium could not be stained using the Ziehl-Neelsen method. Its identification was obtained using $16 \mathrm{~S}$ rRNA amplification and sequencing. Briefly, DNA was extracted from a colony using the QIAamp Tissue kit (Qiagen, Hilden, Germany) following the manufacturer's instructions. Polymerase chain reaction (PCR) amplification of a 1441 bp section was performed using the $\mathrm{fD} 1$ and $\mathrm{rp} 2$ primers as previously described [6]. Following comparison to sequences in the GenBank database (http://www.ncbi. nlm.nih.gov/genbank/; sequence deposited under accession number GenBank:HQ291073), the nucleotide sequence obtained from the PCR product was $100 \%$ identical to unpublished sequences recorded under accession numbers GenBank:EU741181, GenBank: EU741222, and GenBank:EF212022. The first two sequences were obtained from Actinomadura sp. from seawater from Costa Rica, and the latter from an Actinomadura sp. detected in shallow water sediments from Norway. By comparison with those of all officially validated Actinomadura species http://www.bacterio.cict.fr/ index.html, our sequence exhibited a similarity ranging from 95.63\% with Actinomadura libanotica (GenBank: AF163120) to $99.37 \%$ with $A$. meyerae (GenBank:
AY273787). Using the MEGA software [7], we performed a phylogenetic analysis among Actinomadura species and found our patient's strain to be grouped with A. meyerae (Figure 2). The strain was deposited in the Collection de souches de l'Unité des Rickettsies (CSUR, WDCM875) under reference CSUR P15. The antimicrobial susceptibility of strain Timone was assessed using E-test strips (AB BIODISK, Solna, Sweden) on Mueller-Hinton agar. The strain was susceptible to gentamicin (minimal inhibitory concentration $0.5 \mu \mathrm{g} / \mathrm{mL})$, doxycycline $(0.25 \mu \mathrm{g} / \mathrm{mL})$, cotrimoxazole $(1 \mu \mathrm{g} / \mathrm{mL})$ and vancomycin $(2 \mu \mathrm{g} / \mathrm{mL})$, and resistant to amoxicillin $(8 \mu \mathrm{g} / \mathrm{mL})$, imipenem $(4 \mu \mathrm{g} / \mathrm{mL})$, erythromycin $(16 \mu \mathrm{g} / \mathrm{mL})$ and rifampin $(2 \mu \mathrm{g} / \mathrm{mL})$. Subsequently, an oral treatment with cotrimoxazole (sulfamethoxazole, $4800 \mathrm{mg} /$ day and trimethoprim, $960 \mathrm{mg} /$ day) was started and continued for six months. Within 15 days of the onset of antibiotics, our patient's operative wound healed and local inflammatory symptoms resolved. A year later, our patient remains asymptomatic.

\section{Discussion}

Actinomadura species are usually found in surface layers of the soil in semi-desertified areas of tropical and subtropical countries. Most human Actinomadura infections are caused by $A$. madurae and $A$. pelletieri. Both species are agents of mycetoma, a chronic and destructive cutaneous infection that may spread to the bones. Cases of Actinomadura infections have mostly been reported in India, the Middle East, Africa, and South America [1].

In Europe, Actinomadura infections have almost exclusively been diagnosed in immigrants from purported endemic areas [8], but rare endemic cases have

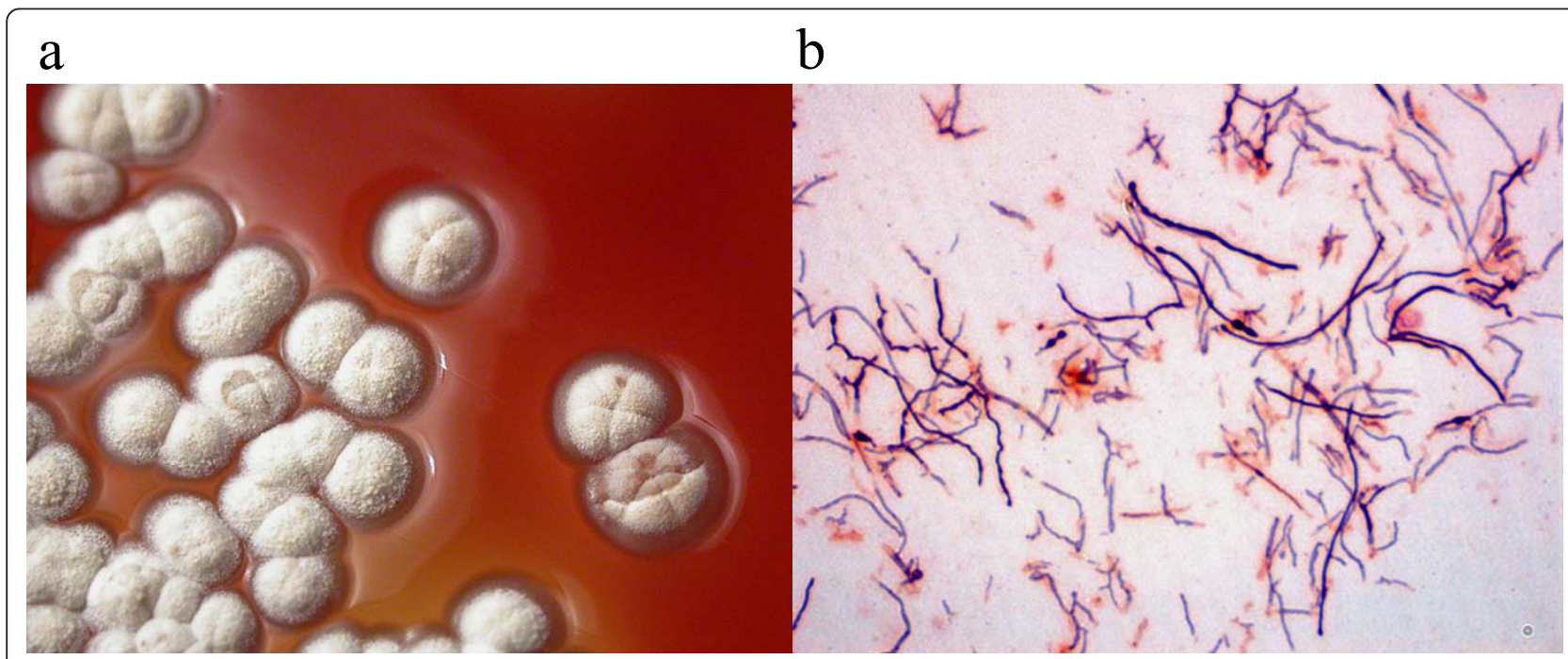

Figure 1 Actinomadura meyerae colonies. A) A meyerae cultivated from our patient's bone biopsy on blood agar; B) Gram staining of an A. meyerae colony. 


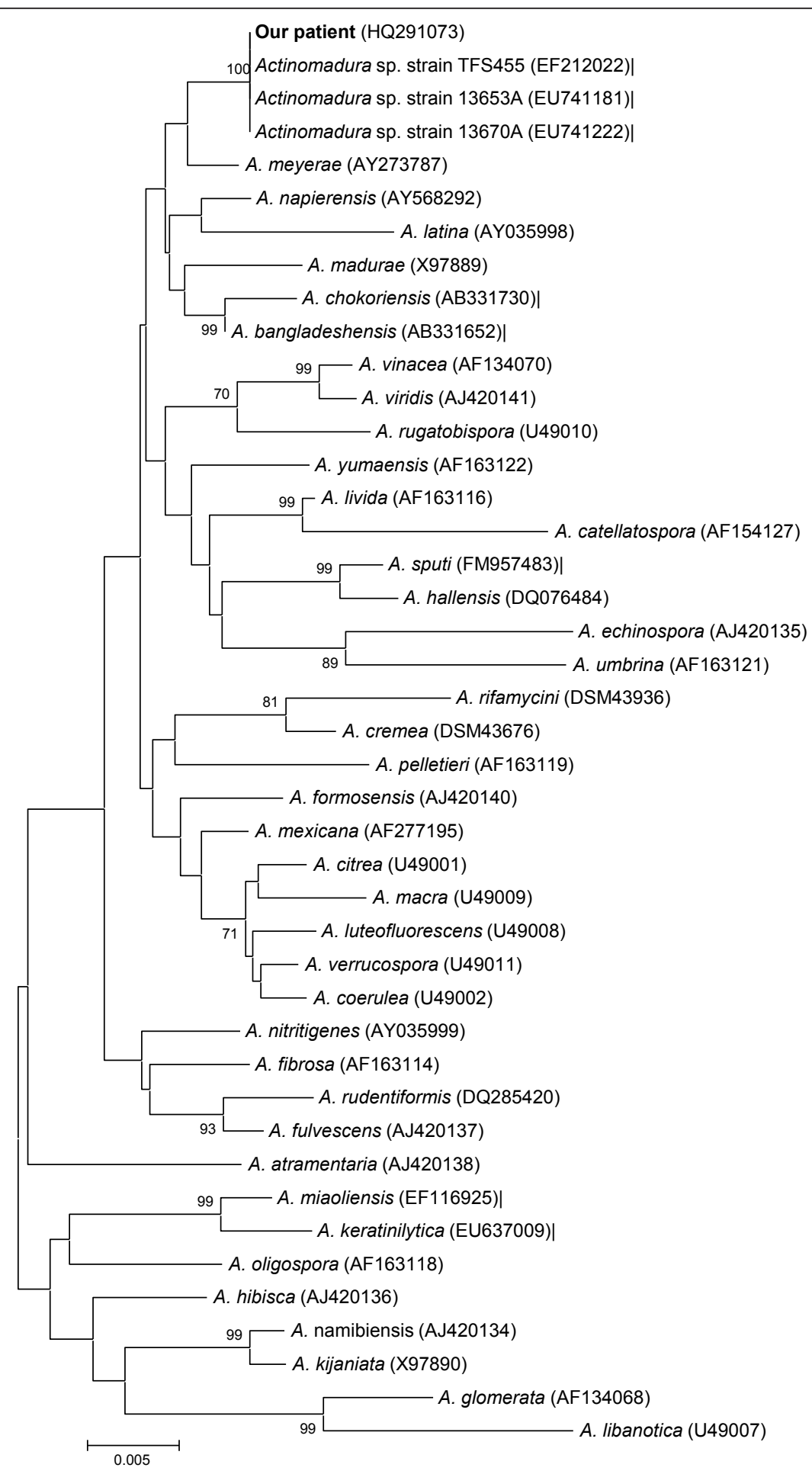

Figure 2 Phylogenetic classification of the Actinomadura meyerae strain isolated from our patient's bone biopsy. Unrooted dendrogram showing the phylogenetic classification of validated Actinomadura species. The analysis was based on 16S rRNA sequence comparison using the neighbor-joining method and MEGA software [7]. Bootstrap values greater than $70 \%$ are indicated at the nodes. The scale bar indicates a $0.2 \%$ sequence dissimilarity. GenBank accession numbers are indicated in parentheses. 
also been reported. In Albania, a 45-year-old man with no history of travel to tropical or subtropical areas was diagnosed as having Actinomadura sp. infection of the foot [2]. In Greece, a 38-year-old man who reported no history of travel abroad presented with a chronic osteitis of the left foot caused by A. madurae [4]. A third autochthonous European case of Actinomadura sp. infection was described in Italy [3]. Recently A. sputi was isolated from the sputum of a German patient [5].

Our report is the fifth reported case of autochthonous Actinomadura infection in Europe, and the first in France. In addition, to the best of our knowledge, this is the first case of $A$. meyerae infection. As we isolated it in pure culture from a bone biopsy, we are confident that it was the causative agent of our patient's bone infection. A. meyerae was first described as Actinomadura meyerii in 2003 [9]. The type strain was isolated from a garden soil in Mexico City [9]. Our patient had not travelled to the usual endemic zones of mycetoma, but had a specific history of wound contamination with hay. This is the likely source of infection, as Actinomadura infection in mycetoma results from the introduction of this agent by minor percutaneous trauma, often associated with plant debris and/or soil. Using cotrimoxazole for six months due to the presence of internal fixation material, the infection improved rapidly, bone healing was obtained and our patient's infection was considered as cured one year later.

\section{Conclusion}

Our report highlights the potential risk of Actinomadura infection in France, in particular in workers exposed to hay in agricultural settings, and identifies $A$. meyerae as a new pathogenic Actinomadura species.

\section{Consent}

Written informed consent was obtained from the patient for publication of this case report and any accompanying images. A copy of the written consent is available for review by the Editor-in-Chief of this journal.

\footnotetext{
Author details

${ }^{1}$ Federation de Microbiologie, Hôpital de la Timone, Marseille, France.

${ }^{2}$ Service de Chirurgie Orthopédique, Hôpital Sainte-Marguerite, Marseille, France.
}

\section{Authors' contributions}

EB and PEF wrote the manuscript while FF performed the bacteriological identification. XF and SP performed the surgical treatment and revised the manuscript for surgical content. JNA and DR corrected the manuscript. All authors read and approved the final manuscript.

\section{Competing interests}

The authors declare that they have no competing interests.
References

1. Hospenthal DR: Agents of mycetoma. In Principles and Practice of Infectious Diseases. Edited by: Mandell GL, Bennett JE, Dolin R. Philadelphia, PA: Elsevier; 2005:2991-2995.

2. De Palma L, Marinelli M, Pavan M, Manso E, Ranaldi R: A rare European case of Madura Foot due to actinomycetes. Joint Bone Spine 2006, 73:321-324.

3. Binazzi M, Papini M: Madura foot by Actinomadura madurae. A further report on an autochthonous Italian case. Mykosen 1983, 26:298-304.

4. Ispoglou SS, Zormpala A, Androulaki A, Sipsas NV: Madura foot due to Actinomadura madurae: imaging appearance. Clin Imaging 2003, 27:233-235

5. Yassin AF, Spröer C, Siering C, Klenk HP: Actinomadura sputi sp. nov., isolated from the sputum of a patient with pulmonary infection. Int $J$ Syst Evol Microbiol 2010, 60:149-153.

6. Weisburg WG, Barns SM, Pelletier DA, Lane DJ: 16S ribosomal DNA amplification for phylogenetic study. J Bacteriol 1991, 173:697-703.

7. Kumar S, Tamura K, Nei M: MEGA3: Integrated software for Molecular Evolutionary Genetics Analysis and sequence alignment. Brief Bioinform 2004, 5:150-163.

8. de Hoog GS, Buiting A, Tan CS, Stroebel AB, Ketterings C, de Boer EJ, et al: Diagnostic problems with imported cases of mycetoma in The Netherlands. Mycoses 1993, 36:81-87.

9. Quintana ET, Trujillo ME, Goodfellow M: Actinomadura mexicana sp. nov. and Actinomadura meyerii sp. nov., two novel soil sporoactinomycetes. Syst Appl Microbiol 2003, 26:511-517.

doi:10.1186/1752-1947-5-32

Cite this article as: Bonnet et al:: Actinomadura meyerae osteitis

following wound contamination with hay in a woman in France: a case report. Journal of Medical Case Reports 2011 5:32.

\section{Submit your next manuscript to BioMed Central} and take full advantage of:

- Convenient online submission

- Thorough peer review

- No space constraints or color figure charges

- Immediate publication on acceptance

- Inclusion in PubMed, CAS, Scopus and Google Scholar

- Research which is freely available for redistribution 